\title{
The Rhône River, France: applying integrative sciences to sustainable management
}

\author{
Hervé Piégay ${ }^{1}$ \\ ${ }^{1}$ Director of the Rhône Valley Human - Environment Observatory (OHM-VR), France
}

\section{Extended abstract}

\subsection{Rhône River issues}

The Rhône River is one of the main European alpine rivers (watershed: $98500 \mathrm{~km}^{2}$; length: $812 \mathrm{~km}$ total, $560 \mathrm{~km}$ in France; mean annual discharge at its mouth: $1700 \mathrm{~m}^{3} \mathrm{~s}^{-1}$; annual flood: $4000 \mathrm{~m}^{3} / \mathrm{s}$ ), and the primary freshwater input to the western Mediterranean basin. It was mainly an upland river transporting gravel up to its delta and continuously supplied in sediments by its Alpine braided tributaries. The Durance River was one of the most active system before being controlled for producing electricity and supplying water for irrigation. The fluvial landscape has been engineered for more than 150 years, leading to altered aquatic and riparian ecosystems and social tensions in terms of local development scenarios. The channel was regulated between 1850 and 1930 for navigation purposes (embankments, groynes, dykes), then dammed for producing electricity (1898-1986: 21 hydroelectric dams, most of them with derivation canals). It is also equipped with 4 nuclear powerplants that use the river water for their cooling.

After more than a century of developments leading to major biological and physical changes due to a significant artificialization of the river corridor, problems and stakes are still existing in terms of human safety, user satisfaction and local development and the aim is now to improve existing conditions and promote a sustainable development, shared by all actors. Today, stakeholders face tension in balancing various user interests regarding nature conservation, flood control, economic and recreational activities, ecological improvement. The French Rhône stakeholders have beencommitted since 2003 in implementing a large inter-regional sustainable development masterplan funded by the European Union (ERDF) called Plan Rhône I and II, focused on the whole river corridor. They created a collective framework grouping local actors to go beyond the complex and sometimes contradictory logics of each of them.

\subsection{Interdisciplinary scientific initiatives}

In this context of active public debate at a large continuum scale, scientists are engaged to provide knowledge to feed discussions and help decision-makers. Scientists have been structured since 2002 within a Rhône basin scientific consortium (ZABR - ILTER site), 
which is interdisciplinary and supported by a set of academic institutions from AixMarseille and Lyon, as well as Besançon, Nîmes, Montpellier, Grenoble and Chambéry. The ZABR community is organised in Observatories and Research sites to cover the different environmental issues existing throughout the catchment. The Rhône River corridor is one of these Research sites, organised since 2010 as a human-environment observatory, labelled at a national level by CNRS (National Scientific Research Center). The Rhône River corridor has thus become an experimental field, a collaborative and integrative science platform, for integrated sciences in terms of partnerships, scientific practices and interdisciplinarity to produce new knowledge and innovate, to inform river managers and citizens, and to help environmental policy implementation. The objective of the "Rhône Valley" Human-Environment Observatory is to provide and share knowledge for improving river management practices, considering simultaneously public policies, human attitudes, biophysical and chemical dynamics. The observatory is based on a coconstruction process of research actions between scientists and stakeholders focused on major practical issues such as the transfer of sediment and associated pollutants, the riversea interactions, the definition of the good ecological potential, the ecological restoration of the river, the program of channel widening, or even the social framework of the Rhône River.

\subsection{An observatory of the sediments}

In this context, an observatory of the Rhône sediments (OSR) was created in 2008, involving an interdisciplinary research team (hydrology, hydraulics, geomorphology, geochemistry, ecotoxicology, geomatics, sedimentology) in strong interactions with river practitioners. The aim of this research group is to provide new scientific knowledge over the Rhône River from Lake Geneva to the Sea for promoting a sustainable management of channel forms and sediment processes. A set of key-questions was asked by stakeholders, which needs several years to be answered: How has the geometry of the channel evolved over the last two centuries? What is the impact of the river geometry and existing infrastructures on the flooding risk or the ecological potential of the river? What is the annual bedload transport? What is the contribution of sediment delivery to the beach evolution of the delta and Languedoc coast? What is the impact of development and management activities such as dredging, channel maintenance or sediment flushing from dam reservoirs? What suspended sediment and contaminant fluxes are transferred to the Mediterranean Sea? Where do they come from and what are their temporal patterns? Are they stored all along the river reach and do they affect the geometry of the bed? Can we predict the sediment transfer and deposition? How can we store and share data between scientists and practitioners for feeding the public debate? Major advances have been done to better characterize and explain the channel evolution of the last century, highlight aquatic and riparian habitat conditions, and assess channel sensitivity to climate and land-use changes. A network of monitoring stations is now operating so that fluxes of suspended sediments and associated contaminants (metal content, organic pollutants and radionuclides) are continuously monitored. An annual quantification of sediment budget has been done and some events such as the floods of May-June 2008 and May 2015 or the sediment flushing operations of June 2012 and June 2016 were also monitored at the scale of the $512 \mathrm{~km}$ river length. Tools and protocols developed for monitoring sediment transfers, archiving data and informing practitioners will be introduced in this keynote lecture. 


\subsection{An ecological restoration program}

Hydraulic engineers, ecologists, geomorphologists and social scientists are also strongly involved since the 1990's in restoration programs, especially through their monitoring for evaluating the success of this policy. An ambitious program of ecological restoration of the Rhône River began at the end of the 90's with eight priority reaches. This program was focused on three thematic axes, namely the restoration of migration routes for fish, the increase of minimum flows in sections by-passed by hydroelectric canals, and the rewatering and reconnection of remnant former channels. The Pierre-Bénite site downstream of Lyon was restored between 1999 and 2000. Three sites in the Upper Rhône River (Chautagne, Belley and Brégnier-Cordon) were then restored between 2004 and 2006. The program is now implemented downstream of Lyon, in the by-passed reaches of Péage-de-Roussillon, Donzère and Montélimar. Scientists have monitored the effects of restoration measures on the physical and biological components (aquatic vegetation, benthic invertebrates and fish). The results, fairly unique over such a long period of time demonstrate minimum flow increase and habitat diversification have significant positive effects on fish and invertebrate communities. Physical monitoring also confirms that such restoration of channel forms is fairly sustained in the Rhône context. Monitoring efforts have been combined with modelling so that practical tools exist to predict a priori what can be potentially the ecological and geomorphic responses of target actions. These tools are used for implementing new restoration actions and recent efforts have been paid to test these tools on other river systems. The restoration policy has also evolved through time and process-based restoration is more and more promoted. Tests and pre-project appraisals are done for augmenting gravel transport and re-eroding banks following groyne fields removal. This research is based on hydraulic modelling combined with intensive geomorphic field surveys (DEM, grain size, particle tracking). Potential benefits and risks linked to promoting gravel augmentation and removing groyne fields are assessed in a restoration context. Dismantling some of the groyne fields has strong potential to provide multiple benefits. It is recommended that managing guidelines should be adapted according to local conditions, as well as expected benefits and needs, and conducted in co-ordination with all actors involved in and affected by the restoration.

\section{Web sites}

1. Plan Rhône : http://www.planrhone.fr/front/index.php

2. Rhône basin scientific consortium (Zone Atelier Bassin du Rhône) : http://www.graie.org/zabr/index.htm

3. Rhône Valley Human - Environment Observatory (Observatoire Homme - Milieux Vallée du Rhône) : http://ohm-vr.org/

4. Observatory of the Rhône sediments (Observatoire des sédiments du Rhône) : http://www.graie.org/osr/

5. Program of ecological restoration of the Rhône River (Suivi scientifique du Programme Décennal de Restauration) : http://restaurationrhone.univlyon1.fr/index.php?action=restauration\&do=presentation 